\title{
The spatial implications of the functional proximity deriving from air passenger flows between European metropolitan urban regions
}

\author{
Malcolm C. Burns · Josep Roca Cladera • \\ Montserrat Moix Bergadà
}

Published online: 25 April 2008

(C) Springer Science+Business Media B.V. 2008

\begin{abstract}
Until recently the traditional spatial configuration of the European geography was based upon the core-periphery model. The 'pentagon', broadly defined as lying between London, Paris, Milan, Munich and Hamburg, was seen as the core area characterised by having the highest concentration of economic development in the European Union (EU), with the remainder of the European territory viewed as peripheral, albeit to varying degrees. In a number of cases such peripheral areas equated with clear regional disparities. The elaboration of the European Spatial Development Perspective (ESDP) (CEC, European spatial development perspective, towards balanced and sustainable development in the territory of the European Union, 1999) challenged this core-periphery model. European spatial planning policies, aimed at encouraging social and economic, and with ever increasing importance, territorial cohesion, seek amongst other aspects to encourage the development of a balanced and polycentric urban system. This paper adopts a network analysis approach to the analysis of air passenger flows between some 28 principal European metropolitan urban regions. The evaluation of these flows contributes to an enhanced comprehension
\end{abstract}

Special Issue: Airline Networks.

M. C. Burns $(\bowtie) \cdot J$. Roca Cladera · M. Moix Bergadà Universitat Politècnica de Catalunya,

Barcelona 08034, Spain

e-mail: malcolm.burns@upc.edu of the spatial dynamics of the European metropolitan territory which goes beyond that deriving from the more standard analyses of the individual components of the urban system. Several indicators are used, deriving from gravitational modelling techniques, to analyse the complexity of the air passenger flows. A multidimensional scaling (MDS) technique is introduced in order to interpret and visualise the resulting spatial configuration and positioning of the different metropolitan centres within the conceptual European 'space of air passenger flows', thereby contrasting with the more traditional map-based geographical image of Europe, based upon Cartesian coordinates.

Keywords European metropolitan system . Network analysis - Air passenger flows · Functional proximity $\cdot$ Physical proximity

\section{Introduction}

In the contemporary European spatial planning discourse, polycentricity plays a key role. As early as 1983, the European Ministers responsible for Regional Planning identified the "balanced socio-economic development of the regions" as one of the fundamental objectives of regional/spatial planning (Council of Europe 1983). While the European Regional Development Fund (ERDF) was created in 1975 with the objective of redistributing part of the Member States' budget 
contributions to the poorest regions of the then European Economic Community (EEC), it was the Single European Act of 1986 which stated the need to strengthen the economic and social cohesion of the Community. The Act laid the basis for the development of cohesion policy, in order to ease the burden of the imminent Single European Market for the southern countries and other regions where disparities were present. However it was the Treaty establishing a Constitution for Europe (2004) which for the first time addressed the territorial aspects of cohesion. The European Commission's Interim Territorial Cohesion Report states categorically that territorial cohesion means "the balanced distribution of human activities across the Union" and that it "translates the goal of sustainable and balanced development assigned to the Union (Article 2 of the Treaty) into territorial terms" (CEC 2004, p. 3).

In order to achieve a balanced and sustainable development of the European territory, the principle of "polycentric and balanced spatial development within the European Union" was included in the European Spatial Development Perspective (ESDP) (CEC 1999), as approved by the Ministers responsible for Spatial Planning. In many ways, the emphasis placed upon polycentricity is aimed at countering the dominant core-periphery territorial structural of Europe, as characterised by Brunet's (1989) dorsal (or Blue Banana) metaphor. Having said that Brunet's report also recognised the importance of the regions of the emerging Mediterranean axis and the Western Atlantic periphery. The same ESPD refers to Europe's 'pentagon', the territory lying between London, Paris, Milan, Munich and Hamburg, representing just $18 \%$ of the whole EU territory, where some $40 \%$ of the European population is contained and where $50 \%$ of the EU's wealth is concentrated. In contrast to Brunet's analysis, Kunzmann and Wegener (1991) proposed an alternative metaphor for the territorial structure of Europe, based upon the bunch of grapes, which was much more in line with contemporary polycentric theory supporting development based upon regional potential.

In order to determine the specific location of such regional potential for encouraging polycentrism on a wide scale, research carried out in the context of the European Spatial Planning Observation Network (ESPON) has developed the concept of the Functional Urban Area (FUA) (ESPON 2004). A total of 1,595 FUAs were identified across the EU27+2 set of countries ${ }^{1}$ which were examined on the basis of population, transport, knowledge, decision making, manufacturing, tourism and administration. Those FUAs with the highest score on the first of these seven indicators were classified as Metropolitan European Growth Areas (MEGAs). The remaining FUAs were categorised as transnational/national FUAs or regional FUAs. A further analysis of the MEGAs on the basis of mass, competitiveness, transport, connectivity and knowledge led to the ranking of the 76 MEGAs into five groupings: global nodes ${ }^{2}$ which are the largest and most competitive urban systems with high connectivity; European engines ${ }^{3}$ so named for their being large and highly competitive, possessing strong human capital with good accessibility; strong MEGAs ${ }^{4}$ representing relatively large and competitive cities, often with strong human capital; potential MEGAs ${ }^{5}$ representing smaller cities, with lower competitiveness, being more peripheral and often with weaker human capital than the strong MEGAs; and finally the weak MEGAs $^{6}$, smaller, less competitive, more peripheral and having lower human capital figures than the potential MEGAs. The highest ranking MEGAs (global nodes and European engines) tend to be located within the pentagon area-Paris, London, Munich, Frankfurt, Milan, Hamburg, Brussels, Stuttgart, Zurich, Amsterdam, Düsseldorf and Cologne, with Madrid, Rome, Copenhagen, Berlin, Barcelona, Stockholm and Vienna all lying outside this area.

\footnotetext{
$\overline{1}$ Belgium, France, Germany, Italy, Luxembourg, The Netherlands, the United Kingdom, Denmark, Ireland, Greece, Spain, Portugal, Austria, Finland, Sweden, the Czech Republic, Estonia, Cyprus, Latvia, Lithuania, Hungary, Malta, Poland, Slovenia, Slovakia, Bulgaria and Rumania (EU27) and Norway and Switzerland.

2 Paris and London.

${ }^{3}$ Munich, Frankfurt, Madrid, Bruxelles, Milano, Roma, Hamburg, Kobenhavn, Zurich, Amsterdam, Berlin, Stockholm, Stuttgart, Barcelona, Düsseldorf, Wien and Köln.

${ }^{4}$ Helsinki, Oslo, Athens, Greater Manchester, Dublin, Goteborg, Torino and Geneve.

5 Lyon, Antwerp, Lisboa, Rotterdam, Malmo, Marseille, Lille, Nice, Napoli, Bern, Praha, Glasgow, Bremen, Toulouse, Warsawa, Budapest, Aarhus, Edinburgh, Bergen, Birmingham, Bilbao, Valencia, Luxembourg, Bologna and Palma de Mallorca.

${ }^{6}$ Bratislava, Turku, Cork, Bordeaux, Le Havre, Genova, Bucuresti, Tallinn, Sofia, Southampton, Sevilla, Porto, Krakow, Vilnius, Ljublijana, Riga, Katowice, Gdansk-Gdynia-Sopo, Poznan, Wroclaw, Lodz, Valletta, Szczecin and Timosoara.
} 
In proposing a spatial order of European cities in the context of globalisation, Taylor and Hoyler (2000) acknowledged that such cities form part of the wider World City Network, drawing upon Castells (1993) and the notion of their forming "nodal centres of the new global economy" (Castells 1993, p. 250). The Lisbon Strategy (2000) sets out the overall objective that the EU will become "the most competitive and dynamic knowledge-based economy in the world by the year 2010" (CEC 2000, p. 2). The Gothenburg Council (CEC 2001) the following year endorsed this, but ensuring that the strategy be linked with sustainable development. In light of these overall objectives, it is considered that there is clear interest in examining the nature of the European urban system as a sub-system of the World System's City System, from the perspective of determining the relations and dynamics between some of Europe's principal metropolitan centres.

This paper takes inspiration from the concept of 'space of flows' and 'network society', proposed by Manuel Castells, in the context of the changes resulting from the informational and technological revolution, and the new industrial space and the new service economy (Castells 1989, 1996). According to Castells, contemporary society is "constructed around flows: flows of capital, flows of information, flows of technology, flows of organisational interaction, flows of images, sounds and symbols". Furthermore such flows are "the expression of processes dominating our economic, political and symbolic life" (Castells 1996, p. 412).

If such an approach is to be adopted to ascertain the nature of the relations between the European metropolitan urban regions, the considerations that need to be addressed relate to (a) the choice of the flows which can realistically be examined, and (b) the selection of the said metropolitan urban regions, in order to proportion results capable of reflecting these relations.

In dealing with this first issue, there is an extensive literature relating to the use of air passenger flows in order to evaluate the concept of World (and European) City Networks (Cattan 1995; Derudder and Witlox 2005; Guimerà et al. 2005; Keeling 1995; Smith and Timberlake 1995a, b, 2001 and 2002; and Timberlake and Ma 2007). Other writers have used air passenger flows as a means of determining different aspects of urban economic development and labour markets (Alkaabi and Debbage 2007; Breuckner 2003; Button and Taylor 2000; Debbage 1999; Debbage and Dalk 2001; and Liu et al. 2007).
Keeling (1995) suggests the connections between world cities and other principal cities of similar, superior or in inferior importance, as well as connections with different urban and rural centres at different territorial scales, are facilitated principally through air transport, telecommunications circuits and non-voice data transfer systems. The most appropriate indication of the role of transport within the world city system derives from the following key considerations:

(1) Global airline flows represent one of the few indices available of transactional flows or interurban connectivity;

(2) Air networks together with their associated infrastructure are the most visible manifestation of world city interaction;

(3) Considerable demand still exists for face-to-face relationships, despite the global telecommunications revolution;

(4) Air transport is the preferred mode of intercity movement for the transnational capitalist class, migrants, tourists and high-value goods; and finally

(5) Airline links form an important component of a city's aspirations to world city status.

It is suggested that the interpretation of the air passenger flows, between the different European metropolitan urban regions fits appropriately within the notion of a 'space of flows'. The evaluation of these flows to determine the degree of interaction between the metropolitan centres and the resulting relations can contribute to another understanding of the European spatial territory, which goes beyond that deriving from a straightforward analysis of the urban system in terms of the geographical position of the cities.

Turning attention to the issue of the selection of the metropolitan urban regions for the sample, in light of the progress made through the ESPON Programme, it is considered wholly appropriate that the sample should derive in the main from those contained within the upper echelons of the classification of the Metropolitan European Growth Areas (MEGA) previously referred to, i.e. the global nodes and European engine classes of the EU15+2. ${ }^{7}$ urban

\footnotetext{
${ }^{7}$ EU15+2 = Belgium, France, Germany, Italy, Luxembourg, The Netherlands, United Kingdom, Denmark, Ireland, Greece, Spain, Portugal, Austria, Finland, Sweden; and Norway and Switzerland.
} 
system $^{8}$. The resulting sample includes 28 European metropolitan urban regions.

A 'network analysis' methodology is adopted in order to help to come to a clear and succinct understanding of the nature of the air passenger flows between the cities of the sample. Several indicators are used, deriving from gravitational modelling techniques, to analyse the complexity of the flows between these cities within the European metropolitan system. Finally a mathematical technique of multidimensional scaling is drawn upon, in order to interpret and visualise the resulting spatial configuration and the positioning of the different cities within the conceptual European 'space of air passenger flows'. Such a vision contrasts with the more traditional map-based geographical image of Europe, based upon Cartesian coordinates, permitting the comparison between the functional and physical proximity of the cities of the sample to the respective centres of gravity.

\section{Network analysis}

For Smith and Timberlake (2002) world cities represent nodes in "multiple networks of economic, social, demographic and informational flows" (p. 118). An approach of this nature enables them to conceptualise these world cities in relational terms, which leads on to consider "mapping cities in terms of their structural relationships to one another" (Smith and Timberlake 2002, p. 118).

One of the limitations in carrying out a network analysis technique to understand an urban system rests in the complex data requirement. Since network analysis concerns relations, the data must itself be a measure of relations. The availability of appropriate data is therefore a crucial consideration. Another such limitation is that data must be available for every city or location in the system. Smith and Timberlake (2002) suggest that "the data requirements can best be understood as an in-flow/out-flow matrix" with "a measure of the relationship between each city pair in

\footnotetext{
${ }_{8}$ Paris, London, Munich, Frankfurt, Madrid, Brussels, Milan, Rome, Hamburg, Copenhagen, Zurich, Amsterdam, Berlin, Stockholm, Stuttgart, Barcelona, Düsseldorf, Vienna, Cologne/ Bonn, Helsinki, Oslo, Athens, Greater Manchester, Dublin, Gothenburg and Geneva, as well as Lisbon and Luxembourg, given their capital city status within the EU15 grouping.
}

the network", and that "formal network analysis on the international city system must be based on a thorough compilation of relational data among all possible pairs of cities to be included in the analysis" (p. 121).

Derudder and Witlox (2005) are critical of analyses of airline data of area subsets in the context of World City Networks. They argue that while "the notion that there is a European or an Asian 'system of cities' or 'urban hierarchy' may initially seem an attractive idea because it appears to provide a coherent subset of cities to study within a regional context" (p. 2379) in the end "depicting the patterns of intercity relations within the Asiapacific region and Europe is only the first step in understanding how these cities operate as world cities. Simply invoking the concept of the world city means that we must extend our vision beyond these area subsets" (p. 2380). While Cattan's (1995) research drew upon gravity modelling techniques to examine the attractivity and international hierarchy of European airports, the overall interest of this paper is more concerned with the relations between the principal airports of the European sub-system comprising the 28 metropolitan cities as described in the Introduction. For this reason it is considered fully justified to draw upon the methodology of the network analytical framework used in World City Network Analysis.

\section{Air passenger data sources}

The first objective of the analysis comprised the construction of a $28 \times 28$ in-flow/out-flow or origindestination matrix of passenger flows, providing data for the 784 city pairs of the European metropolitan urban region space. These flows were taken from publicly available intra-European EUROSTAT transportation data ${ }^{9}$ for 2004 , on the basis of being the most recent year for which such data was available for all of the 28 cities in the sample. ${ }^{10}$ In the cases of Berlin, Paris, Milan, Rome and London, multiple

\footnotetext{
$\overline{9}$ http://epp.eurostat.ec.europa.eu

${ }^{10}$ Other data sources such as the ICAO were considered but were rejected on the basis of not being complete for the sample of 28 cities and appearing to be restricted to returns from a limited number of airlines operating from the airports in question.
} 
airport combinations were used, given that these cities are served by more than one principal airport. ${ }^{11}$

The EUROSTAT database contains data for detailed air passenger flows between airport pairs. ${ }^{12}$ The exploitation of this data source proportioned detailed passenger flows for some 572 of the possible 756 combinations. ${ }^{13}$ The values of the flows were arrived at by taking the median value of (a) the departure flow from one airport to another and (b) the arrival flow at the destination airport from the airport of origin. In a number of cases only one such value-the departure flow from one airport to another or the arrival flow at the destination airport from the airport of origin-was available. Other than the magnitude of the flows, no other details describing for example the socio-demographic characteristics of the passengers were available. In all cases it was assumed that an outgoing journey had a corresponding return-journey, though it is acknowledged that in a minor number of cases the flows would be in just one direction.

Smith and Timberlake (1995b) recognise the requirement for all cells of a matrix to be filled in network analysis. The difference between the maximum number of airport combinations and the combinations for which detailed passenger flows were obtained from the EUROSTAT data source, was overcome by making an estimation of the passenger flows between the airport pairs, based upon complementary data contained within the same EUROSTAT database. ${ }^{14}$

EUROSTAT data provides detailed information of the total number of passengers departing from one EU country to another, broken down to the departures from

\footnotetext{
11 Berlin (Tegel, Tempelhof and Schonefeld); Paris (Charles de Gaulle and Orly); Milan (Linate and Malpensa); Rome (Fiumicino and Campino) and London (Luton, Gatwick, City, Heathrow and Stansted).

$12<<$ Transport $<<$ Air transport $<<$ Air transport measurement $<<$ Detailed air passenger transport by reporting country and routes $<<$ Air passenger transport between the main airports of reporting country and their main partner airports.

13 Although the matrix contains $(n \times n)$ cells, the maximum number of possible combinations is $((n \times n)-n)$, on the basis of the diagonal being zero. No passengers depart from and arrive at the same airport. Even in the case of the London airports, no data was found relating to passenger flows of this nature.

$14<<$ Transport $<<$ Air transport $<<$ Air transport measurement $<<$ Overview of the air passenger transport by country and airports $<<$ Air passenger transport between main airports in each reporting country and partner reporting countries.
}

the individual airports of the country of origin. In the same way it provides detailed information of the total number of passengers arriving in one EU country from another, broken down to the arrivals at the individual airports of the country of arrival. Therefore the absolute and proportional values of passengers leaving any one of the 28 cities of the sample with another country as their destination can be ascertained. Similarly the passengers arriving in one country from another is available and is broken down in terms of the arrival airport, again in absolute and proportional terms.

To provide an example, in the case of Lisbon-Berlin, an estimation was able to be made of the passengers departing from Lisbon and arriving in Berlin was done by firstly ascertaining the passengers (absolute value) arriving in Berlin from Portugal and multiplying that value by the proportion of passengers departing from Portugal for Germany from Lisbon (proportional value). This estimated value was contrasted with the number of passengers (absolute value) departing from Lisbon for Germany, multiplied by the proportion of passengers arriving in Berlin from Portugal (proportional value). The median value of these two calculations was taken as the value of the attraction of Berlin for Lisbon, in the absence of the detailed information concerning the exact flow. In all cases it was assumed, in the absence of information to the contrary, that such flights were direct. Therefore the role of hubs within the European air industry 'space' was not addressed. ${ }^{15}$

However in a number of specific cases, these such estimates are clearly unrealistic, due to the relatively short physical distance separating the cities concerned and the logistical improbability of connectivity between such cities being provided by means of air transportation. These cases include the 20 combinations between Cologne/Bonn-Brussels; Düsseldorf-Brussels; Luxembourg-Brussels; Amsterdam-Brussels; Stuttgart-Zurich; Stuttgart-Frankfurt; Luxembourg-Frankfurt; Luxembourg-Cologne/Bonn; Luxembourg-Düsseldorf; and Stuttgart-Munich, where in each case the physical separation is less than $200 \mathrm{~km}$. In these cases, the 'estimated' flows really need to be treated as 'virtual'

\footnotetext{
15 Possibilities for estimating indirect flows, and as a consequence taking traditional European 'hubs' into consideration, lie within Markov Chain and complex gravity modelling methodologies. Coincidentally the authors are currently developing work in this area, with a view to applying it to air passenger flows within the European space.
} 
flows. ${ }^{16}$ For this reason the final $28 \times 28$ matrix represents a composite picture of the real values for the passenger flows between the city pairs, and the 'realistic' and 'virtual' estimated values for the flows between the other city pairs.

Having achieved values of the air passenger flows for the 756 cells of the $28 \times 28$ origin-destination matrix, the (vertical) totals for each of the airports were calculated as a means of examining the magnitude of the weighting of the hierarchy of each of the 28 airports, with respect to the other airports of the European system i.e. in quantitative terms the number of passengers who depart from each of the airports of origin $X(1, \ldots 27)$ to travel to the destination airport $Y$. The weightings of the hierarchy of the airports are indicated in descending order of magnitude in Table 1.

London stands out far above the others in absolute terms, by having a weighting of almost 18.550 million passengers from the other 27 airports. The highest following value is that of Paris, with 9.915 million passengers, representing almost $50 \%$ of the weighting of London. Frankfurt and Amsterdam follow with 8.3 and 7.5 million passengers respectively, slightly ahead of Madrid (7.3 million passengers) and Barcelona (6.8 million passengers). Milan lies ahead of Rome, ranked 8th and 9th respectively, but in these absolute terms, the other airports of the southern European regional axis all lie well behind-Athens in the 21st position (3.0 million passengers) and Lisbon in the 22nd position (2.9 million passengers).

It is reasonable to question to what extent the exploitation of the EUROSTAT passenger data equated with other specialised passenger data sources. Information was obtained from the European Region of the Airports International Council (ACIEUROPE) denoting the passenger numbers of the Top 50 European Airports in 2003. From this data source London Heathrow stood out, ahead of Frankfurt and Paris (Charles de Gaulle), but combining the multiple airports of London, Paris and Milan, the ordering turns out as follows: London (120 million passengers), Paris (70.5 million passengers), Frankfurt (48.4 million passengers), Amsterdam (40 million passengers), Madrid (35.7 million passengers), Milan and Rome (26.4 and 26.3 million passengers respectively), Munich (24.2 million passengers) and Barcelona (22.7 million passengers).

\footnotetext{
${ }^{16}$ Rail would undoubtedly be the realistic mode of travel for connecting between these cities.
}

Table 1 Ranking of airports in terms of the magnitude of the hierarchy of their weighting (number of air passengers arriving from each of the other 27 airports of the sample) (2004)

\begin{tabular}{|c|c|c|c|}
\hline Reference & Airport(s) & Hierarchy of weighting & Rank \\
\hline 28 & London & $18,549,202$ & 1 \\
\hline 16 & Paris & $9,915,138$ & 2 \\
\hline 5 & Frankfurt & $8,287,006$ & 3 \\
\hline 22 & Amsterdam & $7,527,638$ & 4 \\
\hline 14 & Madrid & $7,260,846$ & 5 \\
\hline 13 & Barcelona & $6,806,624$ & 6 \\
\hline 9 & Munich & $6,757,175$ & 7 \\
\hline 19 & Milan & $6,118,022$ & 8 \\
\hline 20 & Rome & $5,741,471$ & 9 \\
\hline 11 & Berlin & $5,418,468$ & 10 \\
\hline 12 & Copenhagen & $4,976,836$ & 11 \\
\hline 4 & Zurich & $4,317,879$ & 12 \\
\hline 18 & Dublin & $4,201,648$ & 13 \\
\hline 26 & Stockholm & $3,775,540$ & 14 \\
\hline 2 & Brussels & $3,772,381$ & 15 \\
\hline 6 & Hamburg & $3,706,353$ & 16 \\
\hline 8 & Düsseldorf & $3,622,888$ & 17 \\
\hline 1 & Vienna & $3,555,518$ & 18 \\
\hline 3 & Geneva & $3,288,905$ & 19 \\
\hline 27 & Manchester & $3,165,849$ & 20 \\
\hline 17 & Athens & $3,023,125$ & 21 \\
\hline 24 & Lisbon & $2,869,215$ & 22 \\
\hline 7 & Cologne/Bonn & $2,631,369$ & 23 \\
\hline 15 & Helsinki & $2,382,484$ & 24 \\
\hline 23 & Oslo & $2,368,323$ & 25 \\
\hline 10 & Stuttgart & $2,178,891$ & 26 \\
\hline 25 & Gothenburg & $1,679,930$ & 27 \\
\hline 21 & Luxembourg & 513,186 & 28 \\
\hline
\end{tabular}

Source: EUROSTAT (own elaboration)

A correlation was carried out between the 2 sets of data-that deriving from EUROSTAT and the ACI 2003 data, resulting in a correlation coefficient of 0.965 . As a consequence it was considered wholly appropriate to make use of the considerably more extensive EUROSTAT data for the quantitative analysis of the air passenger flows (relations) between the metropolitan urban regions of the sample.

\section{Indicators deriving from the air passenger flows}

In the early 1970s the United Kingdom Department of Labour undertook studies to determine the spatial 
extent of employment areas or Travel to Work Areas (TTWA). The methodology for their definition was first developed by Smart (1974) and then elaborated upon by Coombes et al. (1986). In turn this was adopted in Italy (Sforzi 1991) and even led to orienting European policy (EUROSTAT 1992).

The TTWA methodology was based upon the concepts of self-sufficiency and self-containment ${ }^{17}$ of different labour markets; and the interaction value between the areas being studied. Roca and Moix (2005) recognise the benefits of the interaction value for representing the mutual interaction between two functional spaces. The interaction value considers the bi-directional nature of flows, as well as the weighting of the flows by the origin and destination masses, making it a quasi-gravitational measure.

According to Lee (1973) of all the different types of mathematical models used in planning and transportation studies, gravity models are probably the most popular. Gravity modelling simply adapts and applies to the social sciences relationships pertaining to the physical sciences. In the physical sciences context, these relationships are derived from the Newtonian concept of gravity, whereby the force of gravitational interaction between two bodies is directly proportional to the product of the masses of the bodies and inversely proportional to the square of the distance existing between these masses:

$\mathrm{G}=\left(\mathrm{M}_{i} \times \mathrm{M}_{j}\right) / \mathrm{d}_{i j}^{2}$

where $\mathrm{G}$ is the pull or force of gravity; $\mathrm{M}_{i}$ and $\mathrm{M}_{j}$ are the masses of the two bodies; and $\mathrm{d}_{i j}$ is the distance lying between the two bodies.

In the social sciences context in general, and more specifically in the context of urban systems, "the gravitational pull exerted by two bodies has been interpreted as the amount of interaction between two areas, and the mass of the bodies has been measured in terms of the size or attractiveness of the areas" (Lee 1973, p. 58). Traditional applications of gravity modelling have included the determination of the location of retail centres of a certain magnitude,

\footnotetext{
${ }^{17}$ Self-containment refers to the proportion of the workers who reside and work in the same municipality (RWL) with respect to the resident employed population who might work within or outside the municipality (REP). Self-sufficiency is seen as the proportion between the same RWL and total localised workplaces (LWP).
}

depending upon the pull or attraction generated by the potential spending power from two or more populations, as web as their use in residential location modelling (Wilson 1971).

Returning to the context of employment areas, the interaction value in the employment area context is arrived at by weighting the flow (or at least the square of the flow) by the employment 'masses' of both the sending and receiving areas. The interaction value therefore quantifies the mutual interaction force between the two 'masses', which in this labour market area context are deemed to be the resident employed population (REP) of one sending area and the local workplaces (LWP) of the employment destination.

Following Coombes's approach the first term of the interaction value (IV) equation represents the gravitational attraction of the mass $\mathrm{LWP}_{i}$ upon the mass of $\mathrm{REP}_{j}$, and the second represents the gravitational attraction exerted on $\mathrm{REP}_{j}$ by $\mathrm{LWP}_{i}$. The resulting IV equation can therefore be expressed as:

$\mathrm{IV}=\mathrm{f}_{i j}^{2} /\left(\mathrm{LWP}_{i} \times \mathrm{REP}_{j}\right)+\mathrm{f}_{j i}^{2} /\left(\mathrm{LWP}_{j} \times \mathrm{REP}_{i}\right)$

where

$\mathrm{IV}=\mathrm{IV}_{i j}+\mathrm{IV}_{j i}$

and

$\mathrm{IV}_{i j} \neq \mathrm{IV}_{j i}$

Applying the same methodological approach to the analogy of air passenger flows between two ( $i$ and $j$ ) areas (airports), the same equation can be adopted:

$\mathrm{IV}=\mathrm{f}_{i j}^{2} /\left(\mathrm{DEP}_{i} \times \mathrm{ARR}_{j}\right)+\mathrm{f}_{j i}^{2} /\left(\mathrm{DEP}_{j} \times \mathrm{ARR}_{i}\right)$

where in this case DEP represents air passenger departures from one location to another and ARR represents air passenger arrivals at that latter location from the former.

The interaction value measures the relationship existing between two areas or spatial entities regardless of the intervening distance. For this reason there is truth in Coombes and Openshaw's (1982) assertion that the interaction value is representative of an index for weighting the strengths of the respective commuting flows. Clearly it is the sum of the products of the ratios existing between the flow ' $i, j$ ' (and the transitive ' $j, i$ ') and the masses of origin and destination $\left(\mathrm{LWP}_{i}\right.$ and $\mathrm{DEP}_{j}$ ) (and the transitive masses). However assuming that $f_{i j}^{2}$ is a measure of the force of gravitational 
attraction of $j$ upon $i$, then the interaction value could be rewritten in terms of the concept of functional (as opposed to physical) distance (FD).

In a bi-dimensional space $(i, j)$ and $(j, i)$ from standard Pythagorean geometry it stands that:

$\mathrm{FD}^{2}=\mathrm{FD}_{i j}^{2}+\mathrm{FD}_{j i}^{2}$

Since:

$\mathrm{FD}_{i j}^{2}=1 / \mathrm{IV}_{i j}$

and

$\mathrm{FD}_{j i}^{2}=1 / \mathrm{IV}_{j i}$

then

$\mathrm{FD}_{i j}^{2}=\left(\mathrm{DEP}_{i} \times \mathrm{ARR}_{j}\right) / \mathrm{f}_{i j}^{2}$

and

$\mathrm{FD}_{j i}^{2}=\left(\mathrm{DEP}_{j} \times \mathrm{ARR}_{i}\right) / \mathrm{f}_{j i}^{2}$

The functional distance (FD) is by nature not symmetrical, however in attempting to make it symmetrical the assumption is made that:

$\mathrm{f}_{i j}^{2}=\left(\mathrm{DEP}_{i} \times \mathrm{ARR}_{j}\right) / \mathrm{FD}^{2}$

and

$\mathrm{f}_{j i}^{2}=\left(\mathrm{DEP}_{j} \times \mathrm{ARR}_{i}\right) / \mathrm{FD}^{2}$

SO

$\mathrm{f}_{i j}^{2}+\mathrm{f}_{j i}^{2}=\left[\left(\mathrm{DEP}_{i} \times \mathrm{ARR}_{j}\right) / \mathrm{FD}^{2}\right]$

$+\left[\left(\mathrm{DEP}_{j} \times \mathrm{ARR}_{i}\right) / \mathrm{FD}^{2}\right]$

$=\left[\left(\mathrm{DEP}_{i} \times \mathrm{ARR}_{j}\right)+\left(\mathrm{DEP}_{j} \times \mathrm{ARR}_{i}\right)\right] / \mathrm{FD}^{2}$

and

$\mathrm{FD}^{2}=\left[\left(\mathrm{DEP}_{i} \times \mathrm{ARR}_{j}\right)+\left(\mathrm{DEP}_{j} \times \mathrm{ARR}_{i}\right)\right] /\left(\mathrm{f}_{i j}^{2}+\mathrm{f}_{j i}^{2}\right)$

meaning that

$$
\begin{aligned}
\mathrm{FD}= & \sqrt{ }\left(\left[\left(\mathrm{DEP}_{i} \times \mathrm{ARR}_{j}\right)\right.\right. \\
& \left.\left.+\left(\mathrm{DEP}_{j} \times \mathrm{ARR}_{i}\right)\right] /\left(\mathrm{f}_{i j}^{2}+\mathrm{f}_{j i}^{2}\right)\right)
\end{aligned}
$$

The results of the application of the interaction value (Eq. 5) indicated that the strongest interaction was between Barcelona and Madrid (0.1675); followed by Milan and Rome (0.1394); London and Dublin (0.1193); Gothenburg and Stockholm
(0.0852); Copenhagen and Oslo (0.0626); Cologne/ Bonn and Berlin (0.0601); and Amsterdam and London (0.0433).

The same order was repeated in the application of the functional distance (equation 15), with the closest distance being that between Barcelona and Madrid (3.45); Milan and Rome (3.79); London and Dublin (4.09); Gothenburg and Stockholm (4.85); Copenhagen and Oslo (5.65); Cologne/Bonn and Berlin (5.77); and Amsterdam and London (6.80). The final results of the functional distance calculation between each of the 28 airport combinations are contained in Appendix 1.

\section{Multidimensional scaling}

While the results presented in the previous section enable an appreciation of the individual interaction values and functional distances, as measures of the individual relations, between each metropolitan urban region and the other 27 such urban regions, what is of interest is to explore the nature of the functional distances or relations between all of the metropolitan urban regions. This means treating the system of 28 metropolitan urban regions as a whole and examining the internal dynamics of that system. With this objective in mind, the mathematical technique of multidimensional scaling was drawn upon, enabling a clear and elegant insight into the spatial dynamics of this system.

Multidimensional scaling (MDS) is an appropriate mathematical technique discovering the dimensional nature of the relationships among objects. MDS analysis leads to a rapid geometric representation, or spatial map, of the proximities between different objects. Such a map contributes to the quantification of the nature of the attributes of the said objects, thereby providing the researcher with a visual expression of relationships (O'Connell 1999).

The input data requirement for MDS is that it be in a square, symmetric 1-mode matrix indicating the relationships between a set of objects. Applied to the set of metropolitan urban regions, the set of objects was the metropolitan urban regions themselves and the relationships were the functional distances between the said urban regions deriving from the air passenger flows. However owing to the missing data for Luxembourg (with Gothenburg and Oslo), it was decided to exclude Luxembourg from the sample. Therefore the resulting sample matrix was $27 \times 27$. 
Many different statistical computer programmes are capable of carrying out MDS. In this case the PROXSCAL programme from SPSS was used. Quite simply PROXSCAL automatically performs multidimensional scaling of proximity data in order to ascertain a least-squares representation of the objects on a low-dimensional space. The methodology reduced the 27 dimensions of functional distances (i.e. each $i$ with every possible $j$ ) to just two dimensions $((x, y)$ or Dim_1 and Dim_2).

In the interpretation of an MDS map the axes themselves (Dim 1 and Dim 2) are meaningless and the orientation is completely arbitrary. In order to reach a closer approximation or 'fit' of these results to the European spatial territory, the resulting Dim_1 and Dim_2 coordinates were first inverted over the horizontal and vertical axes, and then rotated around the central point $(0,0)$ leading to the graphical representation in Fig. 1. This illustrates the broad geographical groupings of the metropolitan urban regions around the centre, for example indicating the location of Lisbon, Madrid, Barcelona, Rome, Milan and Athens in the southern quadrants, and the clustering of the Scandinavian, and German and Austrian metropolitan urban regions.

However what is of crucial interest is the proximity of the position of the objects within the two-dimensional plane-in this case the objects are the metropolitan cities. The Euclidean distance from each point to the central point $(0,0)$ was calculated. London $(0.10)$ was the city lying closest to the centre of the European space

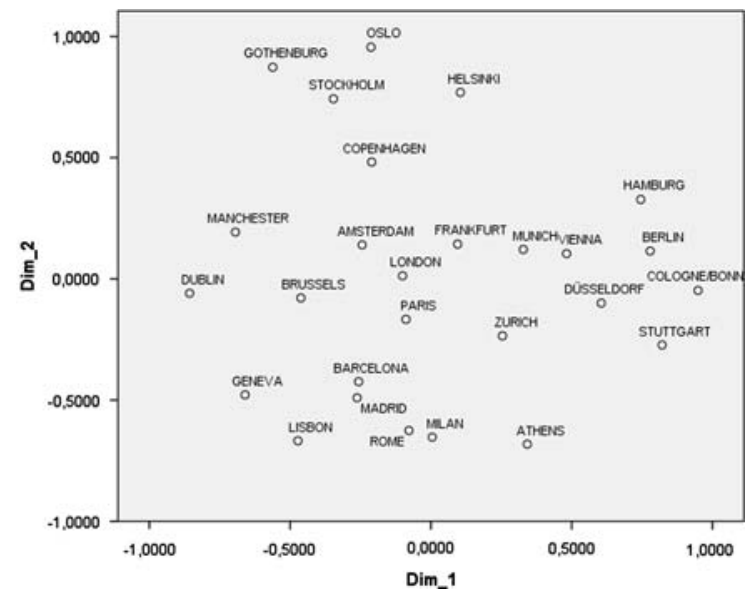

Fig. 1 Graphical representation of the spatial positioning of the cities around the conceptual centre of the 'space of air passenger flows', deriving from the PROXSCAL multidimensional scaling operation of airflows between these principal metropolitan urban regions, followed by Frankfurt (0.17), Paris (0.19), Amsterdam (0.28), Zurich and Munich (0.35), Brussels (0.47), Vienna (0.49), Barcelona (0.50), Copenhagen (0.53), Madrid (0.56), Düsseldorf (0.61), Rome (0.63), Milan (0.65), Manchester (0.72), Athens (0.76), Helsinki (0.78), Berlin (0.79), Hamburg (0.81), Geneva, Lisbon and Stockholm (0.82), Dublin (0.86), Stuttgart (0.87), Cologne/Bonn (0.95), Oslo (0.98) and Gothenburg (1.04) (Table 2).

Figure 2 illustrates the linear rank ordering of the cities from the centre of the 'space of air flows' deriving from the functional distance calculation. From a southern European perspective what is of critical interest is the closer proximity of Barcelona to the centre, than that of Madrid to the centre. On the basis of the functional distance calculation, Barcelona benefits from a higher degree of interaction with the other cities of the sample than Madrid. Moreover of the five countries with two airports in the sample (Great Britain: London and Manchester; Italy: Milan and Rome; Spain: Barcelona and Madrid; Sweden: Gothenburg and Stockholm; and Switzerland: Geneva and Zurich) Spain is the only one which indicates an ostensibly 'secondary' airport having a superior position over the primary one with respect to the functional proximity to the centre of the space of air passenger flows. It is considered that there is a strong message here needing to be acknowledged by governmental agencies in terms of the financing of airports and facilitating licensing for air operators.

In order to compare this functional proximity with physical proximity between the cities, the centre of gravity (COG) between the cities was calculated. ${ }^{18}$ This resulting centre was found to lie to the west of Frankfurt. ${ }^{19}$ The physical distance between each of the cities and the COG was then calculated. ${ }^{20}$ The maximum of all the distances, $1,821 \mathrm{~km}$. corresponding to the distance between Athens and the COG, was

\footnotetext{
$\left.\overline{18}_{\mathrm{X}_{\mathrm{cg}}=\left(\Sigma \mathrm{M}_{\mathrm{i}}\right.} \times \mathrm{X}_{\mathrm{i}}\right) /\left(\Sigma \mathrm{M}_{\mathrm{i}}\right)$, for $\mathrm{i}=1$ to $\mathrm{N}$; and $\mathrm{Y}_{\mathrm{cg}}=(\Sigma \varpi$ $\left.\mathrm{M}_{\mathrm{i}} \times \mathrm{Y}_{\mathrm{i}}\right) /\left(\Sigma \mathrm{M}_{\mathrm{i}}\right)$, for $\mathrm{i}=1$ to $\mathrm{N}$; where $\mathrm{X}_{\text {cg }}$ and $\mathrm{Y}_{\mathrm{cg}}$ are the $\mathrm{X}$ and $y$ coordinates of the Centre of Gravity; $X_{i}$ and $Y_{i}$ are the $x$ and $y$ coordinates of the airports; $M_{i}$ is the mass of the airport (in this case $\mathrm{M}=1$ ); and $\mathrm{N}$ is the number of airports.

${ }^{19}$ LONGITUDE $7.86725^{\circ}$ East and LATITUDE $49.86725^{\circ}$ North.

${ }^{20}$ Great Circle Distance Formula (with radians) $=6,378.8 *$ $\operatorname{arcos}[\sin ($ lat 1$) * \sin ($ lat 2$)+\cos ($ lat 1$) * \cos ($ lat 2$) * \cos ($ lon $2-$ lon1)].
} 
Table 2 PROXSCAL results for the positioning and distances to the centre of the space of air flows for the cities of the sample

\begin{tabular}{|c|c|c|c|c|c|}
\hline Reference & City & Dim_1 & Dim_2 & Dist_centre & Rank_dist_centre \\
\hline 1 & Vienna & -0.41 & -0.28 & 0.49 & 8 \\
\hline 2 & Brussels & 0.40 & 0.25 & 0.47 & 7 \\
\hline 3 & Geneva & 0.43 & 0.69 & 0.82 & 20 \\
\hline 4 & Zurich & -0.32 & 0.12 & 0.35 & 5 \\
\hline 5 & Frankfurt & -0.03 & -0.17 & 0.17 & 2 \\
\hline 6 & Hamburg & -0.57 & -0.58 & 0.81 & 19 \\
\hline 7 & Cologne/Bonn & -0.90 & -0.31 & 0.95 & 25 \\
\hline 8 & Düsseldorf & -0.60 & -0.13 & 0.61 & 12 \\
\hline 9 & Munich & -0.26 & -0.24 & 0.35 & 6 \\
\hline 10 & Stuttgart & -0.86 & -0.05 & 0.87 & 24 \\
\hline 11 & Berlin & -0.68 & -0.40 & 0.79 & 18 \\
\hline 12 & Copenhagen & 0.38 & -0.37 & 0.53 & 10 \\
\hline 13 & Barcelona & 0.08 & 0.49 & 0.50 & 9 \\
\hline 14 & Madrid & 0.06 & 0.55 & 0.56 & 11 \\
\hline 15 & Helsinki & 0.19 & -0.75 & 0.78 & 17 \\
\hline 16 & Paris & 0.02 & 0.19 & 0.19 & 3 \\
\hline 17 & Athens & -0.57 & 0.50 & 0.76 & 16 \\
\hline 18 & Dublin & 0.77 & 0.38 & 0.86 & 23 \\
\hline 19 & Milan & -0.25 & 0.60 & 0.65 & 14 \\
\hline 20 & Rome & -0.16 & 0.61 & 0.63 & 13 \\
\hline 22 & Amsterdam & 0.28 & -0.04 & 0.28 & 4 \\
\hline 23 & Oslo & 0.56 & -0.81 & 0.98 & 26 \\
\hline 24 & Lisbon & 0.19 & 0.80 & 0.82 & 21 \\
\hline 25 & Gothenburg & 0.85 & -0.60 & 1.04 & 27 \\
\hline 26 & Stockholm & 0.60 & -0.56 & 0.82 & 22 \\
\hline 27 & Manchester & 0.72 & 0.08 & 0.72 & 15 \\
\hline 28 & London & 0.10 & 0.03 & 0.10 & 1 \\
\hline
\end{tabular}

Fig. 2 Functional proximity of cities from the centre of the space of European air flows

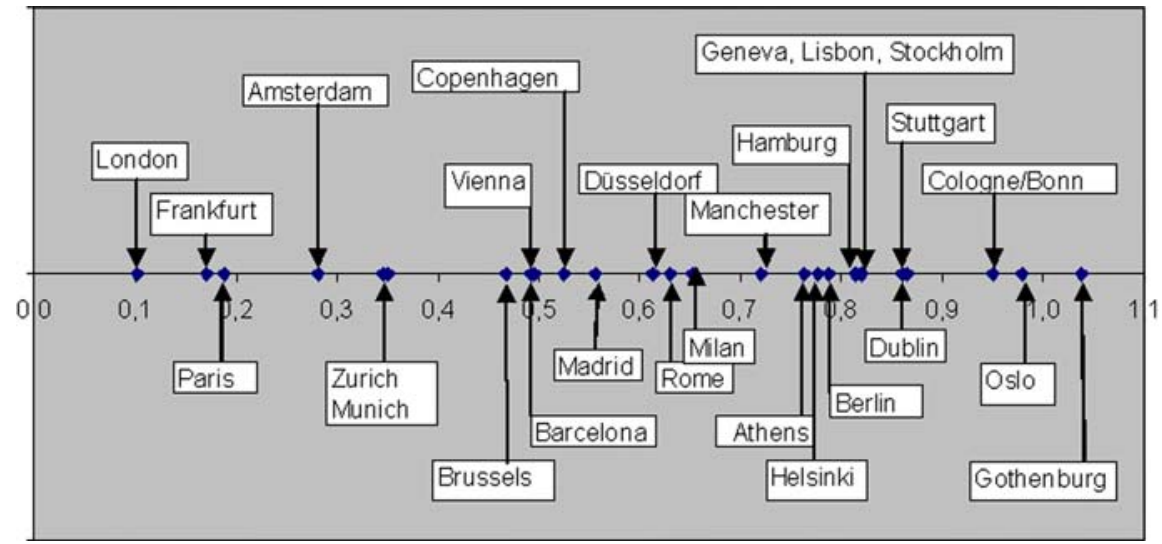

Figure 3 illustrates the corresponding functional and physical proximities of the cities to the centre of the space of European air passenger flows and to the centre of gravity between these cities. Only in seven cases was 
Fig. 3 Functional and physical proximity of the cities from the centre of the space of European air passenger flows and from the centre of gravity

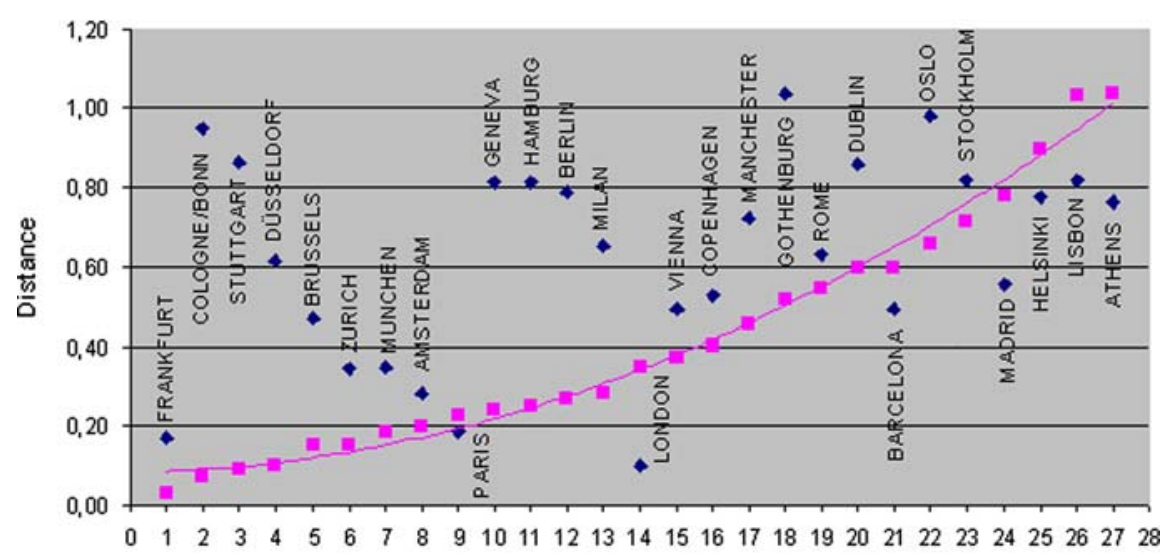

- Functional proximity a Prysical prox imity — Polinómica (Prysical prox imity) the functional proximity inferior to the physical proximity-namely Paris, London, Barcelona, Madrid, Helsinki, Lisbon and Athens. In all the other cases the functional proximity was greater than the physical proximity. Paris and London-the two global nodes of the MEGA classification-were the only two cases lying within the so-called central pentagon area where the physical proximity to the centre of gravity exceeded that of the functional proximity.

Finally Table 3 indicates that the differences between the physical and functional proximities tended to be most pronounced in the case of the cities lying within the more central area, for example in the cases of Cologne/Bonn, Stuttgart, Geneva, Hamburg and Düsseldorf. At the opposite end of the scale, one can see that Paris, with a difference of +0.04 , was almost as close to the centre of the space of air passenger flows, as it was to the centre of gravity between the airports. By contrast London, with a difference of +0.25 , was located further away from the centre of gravity. There was negligible difference between the differences of Barcelona $(+0.10)$ and Helsinki $(+0.12)$, both located at virtual opposite extremes of the EU15+2 territory.

\section{Conclusions}

The principal interest of the results has lain in being able to examine the spatial configuration of the European geographical territory, by virtue of the indicators of abstract functional interaction and proximity between the airports of the metropolitan urban regions. The results show the greater usefulness of the notion of functional proximity over that of physical proximity. The multi-dimensional scaling technique, as demonstrated, has clear applications in networkanalysis approaches, representing an elegant mechanism for reducing the complexity, as the name aptly suggests, of exceedingly complex multidimensional structures, full of intrinsic tensions, to manageable visual representations. However it would be misleading to conclude that the centre point of air passenger flows between the metropolitan urban regions forming part of this study is focussed near to London. Rather, from the other perspective, the conclusion should be that the metropolitan urban region lying closest to the centre of the conceptual 'space of air passenger flows' between the 27 airports, based on 2004 data, is London. The two descriptions are not the same and the difference needs to be appreciated.

If the European policy discourse of polycentrism, contained in the ESPD (CEC 1999) and reiterated within the more recent Territorial Agenda of the European Union (CEC 2007), is aimed at countering the dominance of the core over the periphery of the European territory, through the 'concentrated deconcentration' as suggested by Hall (2004) and focusing on the Metropolitan European Growth Areas, it is suggested that much greater emphasis should be placed on coming to terms with understanding the nature of the relations between the different MEGAs. While considerable in-depth research appears to be being carried out addressing the characteristics of individual polycentric agglomerations in Europe, such as Hall and Pain's (2006) comprehensive analysis, there would seem to be a noticeable absence of research seeking to examine the relations between such areas. Albeit that the research outlined in this paper has examined air 
Table 3 Differentials between the functional and physical proximity of the cities, to the centre of the space of European air passenger flows and to the centre of gravity

\begin{tabular}{|c|c|c|c|c|}
\hline Reference & City & $\begin{array}{l}\text { Functional } \\
\text { proximity }\end{array}$ & $\begin{array}{l}\text { Physical } \\
\text { proximity }\end{array}$ & Differential \\
\hline 7 & $\begin{array}{c}\text { Cologne/ } \\
\text { Bonn }\end{array}$ & 0.95 & 0.07 & -0.88 \\
\hline 10 & Stuttgart & 0.87 & 0.09 & -0.77 \\
\hline 3 & Geneva & 0.82 & 0.24 & -0.57 \\
\hline 6 & Hamburg & 0.81 & 0.25 & -0.56 \\
\hline 25 & Gothenburg & 1.04 & 0.52 & -0.52 \\
\hline 11 & Berlin & 0.79 & 0.27 & -0.52 \\
\hline 8 & Düsseldorf & 0.61 & 0.10 & -0.51 \\
\hline 19 & Milan & 0.65 & 0.28 & -0.37 \\
\hline 23 & Oslo & 0.98 & 0.66 & -0.32 \\
\hline 2 & Brussels & 0.47 & 0.15 & -0.32 \\
\hline 27 & Manchester & 0.72 & 0.46 & -0.27 \\
\hline 18 & Dublin & 0.86 & 0.60 & -0.26 \\
\hline 4 & Zurich & 0.35 & 0.15 & -0.19 \\
\hline 9 & Munich & 0.35 & 0.19 & -0.16 \\
\hline 5 & Frankfurt & 0.17 & 0.03 & -0.14 \\
\hline 12 & Copenhagen & 0.53 & 0.40 & -0.12 \\
\hline 1 & Vienna & 0.49 & 0.37 & -0.12 \\
\hline 26 & Stockholm & 0.82 & 0.71 & -0.11 \\
\hline 20 & Rome & 0.63 & 0.54 & -0.09 \\
\hline 22 & Amsterdam & 0.28 & 0.20 & -0.08 \\
\hline 16 & Paris & 0.19 & 0.23 & +0.04 \\
\hline 13 & Barcelona & 0.50 & 0.60 & +0.10 \\
\hline 15 & Helsinki & 0.78 & 0.90 & +0.12 \\
\hline 24 & Lisbon & 0.82 & 1.04 & +0.22 \\
\hline 14 & Madrid & 0.56 & 0.78 & +0.23 \\
\hline 28 & London & 0.10 & 0.35 & +0.25 \\
\hline 17 & Athens & 0.76 & 1.04 & +0.28 \\
\hline
\end{tabular}

passenger flows alone ${ }^{21}$ these results have proportioned a clear image of the spatial positioning of the 27 metropolitan urban regions with respect to one another, deriving from the conceptual space of air passenger flows, to indicate a very different sort of positioning to that traditionally derived from a strictly geographical perspective. It is considered that this alternative spatial vision is of sufficient importance to warrant further research and investigation into the different sorts of relations which exist between the metropolitan urban

\footnotetext{
21 A more thorough reading of the spatial positioning would have been achieved taking into consideration multi-modality, i.e. air, rail and road passenger flows. Indeed this would have compensated in part for the absence of air passenger flows in the cases requiring the input of the 'virtual' passenger flows. It is the authors' intention to carry out future research examining multi-modality at the European level.
}

regions, and other levels of the European urban system, through different sorts of flows, such as trade, finance, tourism and information to name just a few. In the future rail passenger flows, in the light of the fully functioning network of high speed trains, by virtue of the Trans European Network (TEN), will undoubtedly generate interesting spatial visions as well. Indeed such previsions were given a graphical representation in the time-space cartography produced by the University of Dortmund in the early 1990s (Spiekermann and Wegener 1994). This could only lead to an enhanced understanding of European territorial dynamics, which would be of enormous benefit to policy makers and politicians alike at all levels, faced with the task of seeking the balance between competitivity and complementarity within the overall context of sustainable territorial development. 


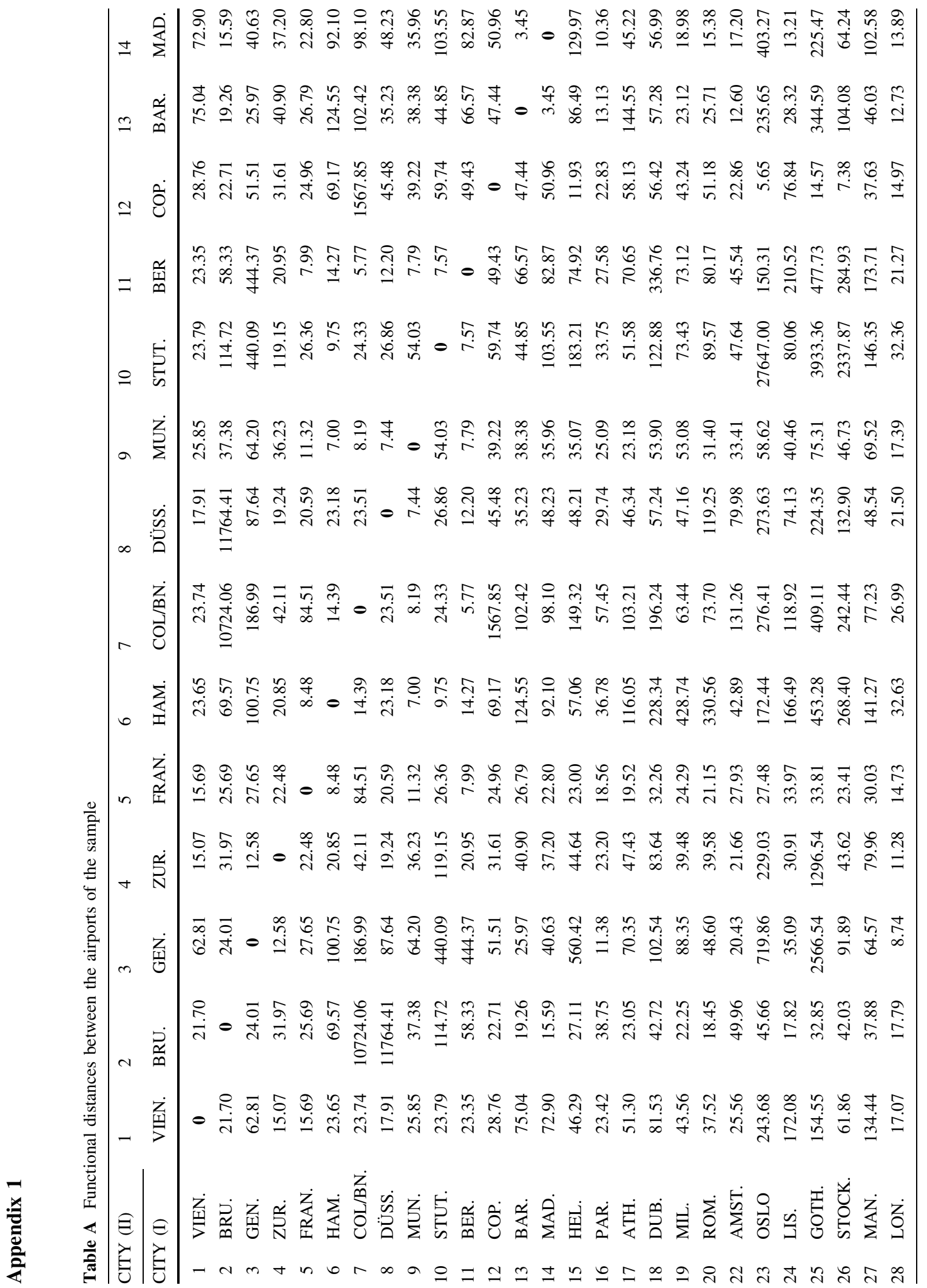




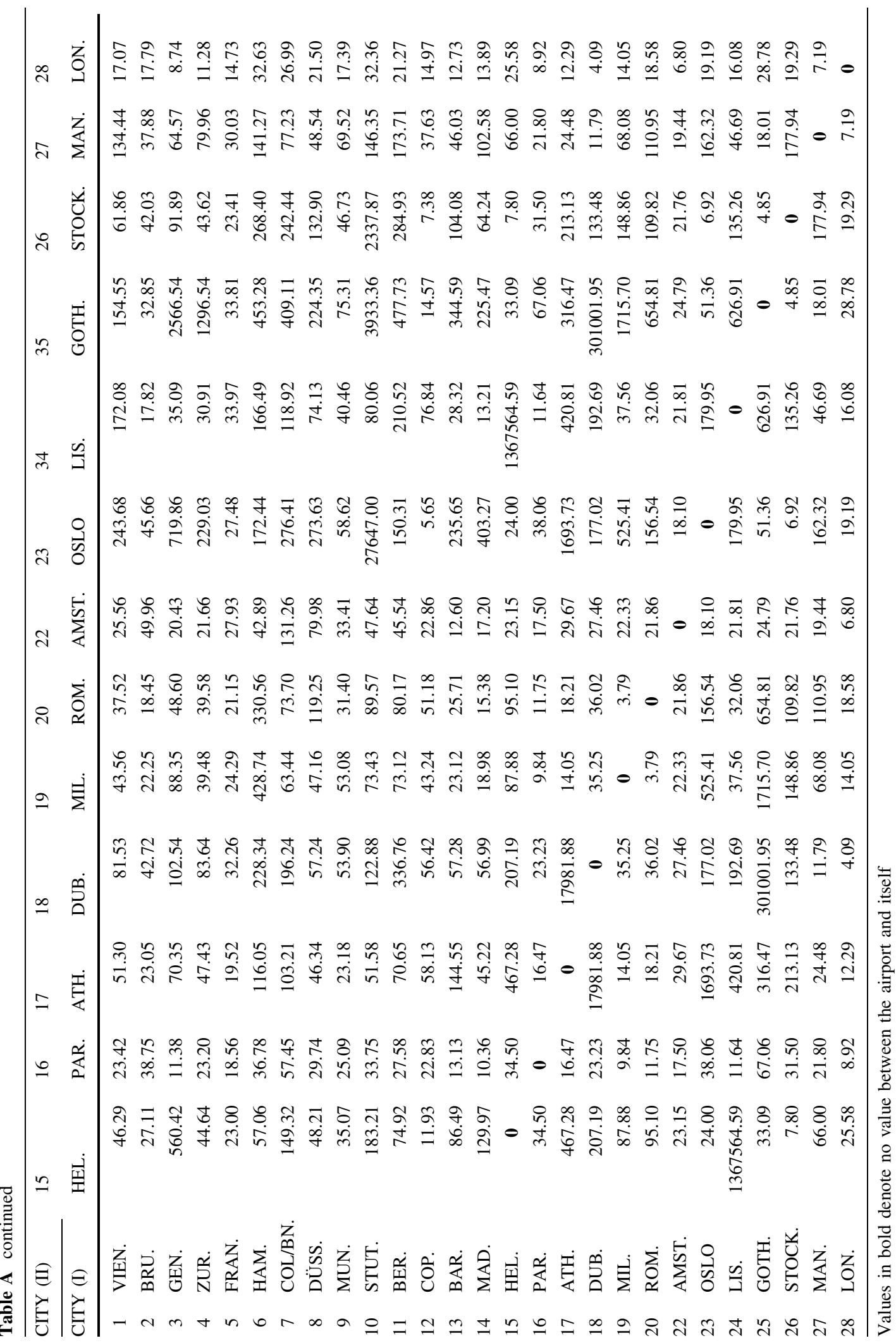




\section{References}

Alkaabi, K. A., \& Debbage, K. (2007). Air passenger demand and skilled labor markets by US metropolitan area. Journal of Air Transport Management, 13(3), 121-130.

Brueckner, J. K. (2003). Airline traffic and urban economic development. Urban Studies, 40(8), 1455-1469.

Brunet, R. (1989). Les villes européennes. Report for the DATAR. Paris: Groupement d'Intérêt Public.

Button, K., \& Taylor, S. (2000). International air transportation and economic development. Journal of Air Transport Management, 6(4), 209-222.

Castells, M. (1989). The informational city: Information technology, economic restructuring, and the urban-regional process. Oxford: Blackwell.

Castells, M. (1993). European cities, the informational society and the global economy. Tijdschrift voor Economische en Sociale Geografie, 84, 247-257.

Castells, M. (1996). The information age: Economy society and culture. Vol I: The rise of the network society. Oxford: Blackwell.

Cattan, N. (1995). Attractivity and internationalisation of major European cities: The example of air traffic. Urban Studies, 32(2), 303-312.

CEC. (1999). European spatial development perspective, towards balanced and sustainable development in the territory of the European Union. Luxembourg: Office for Official Publications of the European Communities.

CEC. (2000). Lisbon European Council 23 and 24 March 2000, Presidency Conclusions. Retrieved Jul 30, 2007, from http://www.europarl.europa.eu/summits/lis1_en.htm.

CEC. (2001). European Council Göteborg, Conclusions of the Presidency, 15 and 16 June 2001. Retrieved July 30, 2007, from http://www.europarl.europa.eu/summits/pdf/got1_en.pdf.

CEC. (2004). Interim Territorial Cohesion Report. Luxembourg: Office for Official Publications of the European Communities.

CEC. (2007). Territorial Agenda of the European Union, Towards a more competitive and sustainable Europe of diverse regions. Retrieved July 11, 2007 from http://www. bmvbs.de/Anlage/original_1005295/Territorial-Agenda-ofthe-European-Union-Agreed-on-25-May-2007-barrierfree.pdf.

Coombes, M., Green, A. E., \& Openshaw, S. (1986). An efficient algorithm to generate official statistical reporting areas: The case of the 1984 travel-to-work-areas revision in Britain. Journal of the Operational Research Society, 37, 943-953.

Coombes, M., \& Openshaw, S. (1982). The use and definition of travel-to-work areas in Great Britain: Some comments. Regional Studies, 16, 141-149.

Council of Europe European Conference of Ministers responsible for Regional Planning (CEMAT). (1983). European charter for regional/spatial planning, adopted on May 20th 1983 in Torremolinos, Spain.

Debbage, K. (1999). Air transportation and urban-economic restructuring: Competitive advantage in the US Carolinas. Journal of Air Transport Management, 5(4), 211-221.

Debbage, K., \& Delk, D. (2001). The geography of air passenger volume and local employment patterns by US metropolitan core area: 1973-1996. Journal of Air Transport Management, 7(3), 159-167.

Derudder B., \& Witlox F. (2005). An appraisal of the use of airline data in assessing the world city network: A research note on data. Urban Studies, 42(13), 2371-2388.

ESPON (2004). ESPON Project 1.1.1. Potentials for polycentric development in Europe, Final Report, ESPON.

EUROSTAT. (1992). Study of employment zones. Regional statistics and accounts. Luxembourg: EUROSTAT.

Guimerà, R., Mossa, S., Turtschi, A., \& Amaral, L. (2005). The worldwide air transportation network: anomalous centrality, community structure and cities' global roles. Proceedings of the National Academy of Sciences of the United States of America, 102(22), 7794-7799.

Hall, P. (2004). World cities, mega-cities and global mega-city regions. GaWC Annual Lecture. Loughborough University: Globalisation and World Cities Study Group and Network.

Hall, P., \& Pain, K. (2006). The polycentric metropolis. Learning from mega-city regions in Europe. London: Earthscan.

Keeling, D. J. (1995). Transport and the world city paradigm. In P. Knox \& P. J. Taylor (Eds.), World cities in a worldsystem. Cambridge: Cambridge University Press.

Kunzmann, K., \& Wegener, M. (1991). The pattern of urbanisation in Western Europe 1960-1990, Report for the Directorate General XVI of the Commission of the European Communities as part of the study Urbanisation and the Function of Cities in the European Community, IRPUD, Dortmund.

Lee, C. (1973). Models in planning. Oxford: Pergamon Press.

Liu, Z-J., Debbage, K., \& Blackburn, B. (2007). Locational determinants of major US air passenger markets by metropolitan areas. Paper presented at the 2007 Meeting of the Association of American Geographers, 17-21 April, San Francisco.

O'Connell, A. (1999). Book review of 'modern multidimensional scaling: Theory and practice', by I. Borg \& P. Groenen (1997). New York: Springer-Verlag in Journal of the American Statistical Association, 94(445), 338-339.

Roca, J., \& Moix, M. (2005). The interaction value: its scope and limits as an instrument for delimiting urban systems. Regional Studies, 39(3), 357-373.

Sforzi, F. (1991). La delimitazioni dei sistemi urbani: definizione, concetti e metodi. In C. Bertglia \& A. La Bella (Eds.), I sistemi urbani Milan: Franco Angeli.

Smart M. W. (1974). Labour market areas: Uses and definitions. Progress in Planning, 2, 238-353.

Smith, D. A., \& Timberlake, M. (1995a). Conceptualising and mapping the structure of the world system's city system. Urban Studies, 32(2), 287-302.

Smith, D. A., \& Timberlake, M. (1995b). Cities in global matrices: Toward mapping the world-system's city system. In P. Knox \& P. J. Taylor (Eds.), World cities in a world-system Cambridge: Cambridge University Press.

Smith, D. A., \& Timberlake, M. (2001). World city networks and hierarchies, 1977-1997. American Behavioral Scientist, 44(10), 1656-1678.

Smith, D. A., \& Timberlake, M. (2002). Hierarchies of dominance among World Cities: A network approach. In 
S. Sassen (Ed.), Global networks, linked cities London: Routledge.

Spiekermann, K., \& Wegener, M. (1994). The shrinking continent: New time space maps of Europe. Environment and Planning B: Planning and Design, 21, 653-673.

Taylor, P. J., \& Hoyler, M. (2000). The spatial order of European cities under conditions of contemporary globalization. Tijdschrift voor Economische en Social Geografie, 91(2), 176-189.
Timberlake, M., \& Ma, X. (2007). Shanghai's increasing centrality in airline passenger networks. Paper presented at the 2007 Meeting of the Association of American Geographers, 17-21 April, San Francisco.

Wilson, A. G. (1971). Entropy in urban and regional modelling. London: Pion. 